\title{
Ambientalização curricular na educação superior: características e tendências de dissertações e teses brasileiras (1987-2009)
}

\author{
Juliana Rink \\ julirink@gmail.com \\ orcid.org/0000-0003-3491-8306 \\ Universidade Estadual de Campinas \\ (Unicamp), Campinas, São Paulo, Brasil \\ Jorge Megid Neto \\ imegid@gmail.com \\ orcid.org/0000-0003-0829-9548 \\ Universidade Estadual de Campinas \\ (Unicamp), Campinas, São Paulo, Brasil
}

\begin{abstract}
RESUMO
Esta pesquisa integrou um projeto interinstitucional de identificação, análise e avaliação das dissertações e teses brasileiras em Educação Ambiental, defendidas no período 1987-2009 (Projeto EArte), e buscou responder ao seguinte problema de investigação: que concepções e práticas de ambientalização curricular podem ser observadas nas dissertações e teses em EA voltadas para formação de professores e profissionais educadores ambientais? Teve por objetivo analisar os processos de ambientalização curricular propostos e/ou estudados por essa parcela da produção acadêmica nacional. O levantamento de documentos foi realizado junto ao Banco de Teses do Projeto EArte, cujos dados foram obtidos a partir do Banco de Teses da Capes e outras fontes de informação da produção científica brasileira. Identificamos 85 dissertações e teses com respeito à temática desta pesquisa, de um universo de 2.151 trabalhos de pesquisa em EA produzidos no âmbito da pós-graduação brasileira até 2009. Além de um panorama geral da produção (ano de defesa, instituições produtoras, grau de titulação acadêmica entre outros aspectos), os documentos foram analisados em relação aos seguintes descritores de caráter curricular-ambiental: modalidade do curso de licenciatura; área curricular, tipo de estudo; concepção de educação ambiental; e concepção de currículo. Dentre os resultados obtidos, destacamos que os trabalhos abrangem, predominantemente, as licenciaturas em Ciências Biológicas e Pedagogia; a maior parte desenvolveu diagnóstico curricular de cursos e/ou de disciplinas específicas, sendo que poucas pesquisas implementam e avaliam propostas de ambientalização curricular; a maioria dos processos de ambientalização investigados pelos trabalhos traz perspectivas não críticas de EA, ligadas às tendências conservacionista e pragmática; há presença incipiente da perspectiva de EA crítica no conjunto de documentos, ainda que de modo prognóstico e teórico. $O$ estudo indicou, também, a persistência do debate em relação à disciplinarização da temática ambiental na formação inicial de professores e educadores ambientais e apontou para diversos condicionantes institucionais que favorecem processos de ambientalização curricular restritos e pontuais.
\end{abstract}

PALAVRAS-CHAVE: Ambientalização Curricular. Pesquisa Educacional. Educação Superior. Educação Ambiental. 


\section{INTRODUÇÃO}

O senso comum, reforçado pelos meios de comunicação social e pelas análises de gestores da educação pública, considera a formação dos professores precária e causa principal dos problemas da educação básica brasileira. Em geral, atribui-se ao professor a responsabilidade pelas mazelas educacionais, esquecendo-se dos fatores sociais, econômicos e políticos intervenientes, da falta de condições pedagógicas e de infraestrutura da grande maioria das escolas brasileiras, do desprestígio social da profissão de magistério entre outras causas. Entretanto, mesmo que o professor não seja o responsável por esse cenário, pelo menos deverá estar preparado para enfrentá-lo e atenuá-lo. Assim, aperfeiçoar os processos de formação inicial e continuada de professores, além de valorizar suas condições profissionais, são ações imprescindíveis para se obter uma educação básica de qualidade no país.

Ao considerarmos o campo da Educação Ambiental (EA), podemos discutir outras questões sobre formação de professores. A EA deve estar presente de modo interdisciplinar, transversal e holístico, nos âmbitos formal e não formal de ensino, tornando-se um elemento chave para a transformação social na busca pela sustentabilidade (LEFF, 2001). É importante ressaltar que partimos do pressuposto que as raízes e bases epistemológicas, filosóficas e políticas da EA não podem ser dissociadas do movimento ambientalista moderno, caracterizado por McCormick (1992) como maior envolvimento ativista e político da sociedade em relação às questões ambientais, delineado após a Segunda Guerra Mundial. Autores como Leff (2001), Carvalho (2004), Caride Gómez (2007), Pavesi (2007), Farias (2008), entre outros, apontam para a importância que a realização de conferências internacionais teve para disparar as discussões sobre a inserção da temática ambiental na Educação Superior em instituições de todo o mundo.

Caride Gómez (2007) pontua que a formação universitária é essencial para articular formação profissional e pesquisa acadêmica com uma visão complexa e sistêmica da crise ambiental. $\mathrm{O}$ autor considera que a temática ambiental se encontra no entremeio do debate sobre Educação Superior, desde a década de 1970, sendo corroborada pelos acordos políticos mundiais e documentos regulatórios. Contudo, Herremans e Allwright (2000) apontam para a lentidão com a qual as preocupações ambientais são incorporadas na Educação Superior, no mundo todo, mesmo com diversos documentos e declarações globalmente reconhecidos.

No Brasil, conforme as Diretrizes Curriculares Nacionais para a Educação Ambiental (DCNEA), publicadas em 2012 (BRASIL, 2012) a EA deve estar presente em todos os níveis e modalidades de ensino, devendo as instituições de ensino promovê-la de forma integrada e articulada em todas as modalidades e cursos de graduação e pós-graduação.

Sob essa perspectiva, devemos voltar nossos olhares para a universidade. Por meio de seu compromisso social, ela assume a responsabilidade de estreitar as relações entre a pesquisa e os demais setores da sociedade. Marcote e Suárez (2005) defendem que as Instituições de Ensino Superior (IES) têm o papel de formar os pensadores-profissionais, que poderão levar a cabo a revolução moral, cultural e cognitiva rumo a uma mudança paradigmática. 
Para Caride Gómez (2007), a Educação Superior foi assumida pelos órgãos mundiais, nos anos 1990, como uma das protagonistas das transformações sociais, e o segmento tem sofrido uma de suas maiores expansões de contingente e estrutura. Contudo, Caride Gómez (2007) critica a formação que os indivíduos recebem na universidade, centrada na aquisição de conhecimento técnico, focada na especialização funcional e nas demandas pontuais e imediatas do mercado. Para o autor supracitado, os cursos de graduação acabam negligenciando o caráter crítico e reflexivo na formação profissional, não contribuindo para a mudança social que anunciam, tampouco conseguem garantir a sobrevivência dos profissionais em um mercado de trabalho instável e fluido.

Nesse sentido, concordamos com Carvalho, Cavalari e Santos Silva (2015, p. 47), sobre o fato de a universidade ser compreendida como "locus privilegiado para a produção e difusão de conhecimentos, valores e ações que fomentam a participação política diversa, acerca da temática ambiental”. Esse processo de incorporação da temática ambiental nas universidades tem sido amplamente difundido como "ambientalização curricular dos Estudos Superiores" (JUNYENT; GELI; ARBAT, 2003), referencial produzido dentro das iniciativas da Rede de Ambientalização Curricular no Ensino Superior (Rede ACES), constantemente referenciada em estudos sobre a EA na Educação Superior. Formada por onze universidades (sendo cinco latino-americanas e seis europeias), a Rede desenvolveu uma série de encontros e publicações acadêmicas ao longo dos anos 2000, tratando de vários aspectos a respeito da ambientalização curricular na Educação Superior, além da criação de grupos de estudos, linhas de pesquisas e publicações decorrentes nas universidades participantes.

Embora não tenha sido o primeiro grupo a buscar uma definição para o termo, a Rede se posicionou diante da ambientalização curricular como um processo complexo de integração harmônica e transversal de conhecimento, entendido como procedimentos, atitudes e conceitos geradores de valores e ações de participação com comprometimento político, buscando promover um questionamento profundo sobre os conhecimentos e sua produção, ao longo do trajeto da formação integral dos estudantes (JUNYENT; GELI; ARBAT, 2003).

Para Carvalho, Cavalari e Santos Silva (2015), tais processos de ambientalização curricular se configuram como respostas de natureza política das instituições de ensino superior às demandas da sociedade atual. Em nossa perspectiva, a incorporação de conteúdos, enfoques e perspectivas metodológicas voltadas para a temática ambiental nos currículos da Educação Superior pode acontecer em diferentes momentos e intensidades, desde um programa de uma disciplina até a reestruturação global de cursos, configurando processos de ambientalização curricular mais restritos e pontuais ou mais amplos e abrangentes. Por outro lado, consideramos que tais processos podem estar presentes em outros programas e ações, tais como a gestão ambiental dos campi, ações educativas de sensibilização da comunidade universitária e demais programas educacionais, os quais podem ou não estar vinculados aos currículos de cursos de graduação ou pós-graduação. No contexto deste estudo, discutiremos ambientalização exclusivamente do ponto de vista dos currículos e dos cursos de formação.

Esse contexto nos motivou a olhar para a produção científica na universidade vinculada ao assunto. Embora recente, sabemos que a pesquisa acadêmica e 
científica sobre EA no Brasil tem crescido de maneira significativa, intensificandose a partir de 1990. Megid Neto (2009) estima a existência de mais de 3000 dissertações e teses produzidas no Brasil no campo da EA, defendidas entre 1981 e 2010. Essa quantidade de pesquisas sobre a temática ambiental cresce ainda mais se considerarmos a existência de estudos e investigações não vinculados, direta ou indiretamente, a dissertações e teses, sendo divulgados na forma de artigos científicos, livros, entre outros meios. Por outro lado, é importante ressaltar que, apesar da grande quantidade de informações e trabalhos desenvolvidos pelos vários segmentos enredados na pesquisa em EA no país, tal produção encontra-se dispersa e pouco sistematizada, o que pode comprometer a retroalimentação dos resultados nos cursos de formação inicial. Isso evidencia um abismo entre a inserção de resultados das pesquisas acadêmicas no contexto da EA de sua prática efetiva na Educação Superior. Assim, é importante conhecer em profundidade tal produção, não só identificando-a, mas, também, contribuindo em sua análise e divulgação, estimulando novos debates em torno da problemática.

Nesse sentido, desenvolvemos esta pesquisa visando elucidar o seguinte problema: que concepções e práticas de ambientalização curricular podem ser evidenciadas nas dissertações e teses em EA voltadas para formação de professores e profissionais educadores ambientais? Tivemos por objetivo geral analisar os processos de ambientalização curricular propostos e/ou investigados pelos trabalhos de pesquisa em EA voltados para a formação de professores e profissionais educadores ambientais, defendidos em programas de pós-graduação brasileiros no período de 1981 a 2009.

Como pressupostos, entendemos que as características de um processo de ambientalização curricular estão ligadas às idiossincrasias, histórias de vida e concepções teóricas e metodológicas de grupos sociais e indivíduos. Tais fatores influenciam e são influenciados pelas concepções de ambiente, educação ambiental e currículo dos diferentes atores envolvidos nos processos. Em relação à $E A$, os estudos teóricos efetuados ao longo da pesquisa nos levaram a considerar o referencial de Layrargues e Lima (2014) e as macrotendências da EA por eles propostas: conservacionista, pragmática e crítica. Para as concepções de currículo, assumimos o referencial de Silva (2004), que agrupa as teorias curriculares em tradicionais, críticas e pós-críticas. Esses referenciais serão tratados em conjunto com a análise dos dados desta pesquisa.

\section{PROCEDIMENTOS METODOLÓGICOS}

Conforme Megid Neto (2009), sempre que um campo de conhecimento atinge uma produção significativa, do ponto de vista quantitativo, é desejável que sejam realizados estudos sistemáticos que possibilitem não só conhecer as características e tendências da mesma, mas também ampliar sua divulgação. As "pesquisas de estado da arte" cumprem esse papel e "[...] são fundamentais para acompanhar o processo de constituição de uma área do conhecimento, porque revelam temas que permanecem ao longo do tempo, assim como os que esmaecem, os que despontam promissores e os que ficam totalmente esquecidos (ANDRÉ, 2009, p. 43). São estudos com características de revisão bibliográfica mas de natureza avaliativa e não apenas descritiva (GAY, 1981). Buscam, assim, identificar a produção em determinado campo científico ou temático, analisar suas 
características e tendências, apontar avanços, contribuições e eventuais lacunas ou limitações, reconstruindo os conhecimentos elaborados no conjunto de pesquisas em uma perspectiva integrativa e avaliativa e, por consequência, favorecendo uma divulgação mais adequada e profunda dessa produção.

Nesse sentido, este estudo se caracteriza como uma pesquisa do tipo estado da arte e integra as iniciativas do Projeto EArte - A Educação Ambiental no Brasil: análise da produção acadêmica (dissertações e teses). Originariamente, o projeto envolvia grupos de pesquisa de três universidades públicas brasileiras: Universidade Estadual Paulista "Júlio de Mesquita Filho (UNESP) - campus Rio Claro, Universidade Estadual de Campinas (UNICAMP) e Universidade de São Paulo (USP) - campus Ribeirão Preto. Atualmente, inclui pesquisadores da Universidade Federal Fluminense (UFF), Universidade Federal do Triangulo Mineiro (UFTM), Universidade Federal do Paraná (UFPR) e o Instituto Federal de Educação Tecnológica (IFSP) - campus Itapetininga.

O Projeto EArte realiza um amplo levantamento das dissertações e teses brasileiras no campo da EA, disponibilizando um banco de dados que conta com 4.514 referências disponíveis ao público externo, compreendendo o período 19812016. O ano de 1981 corresponde ao ano de defesa dos três primeiros trabalhos em nível de pós-graduação no campo da $\mathrm{EA}^{1}$.

A partir do Banco de Teses e Dissertações do Projeto EArte (disponível em www.earte.net), identificamos o conjunto de documentos relacionados à Educação Superior, ou seja, pesquisas que abordaram cursos, programas ou disciplinas no âmbito da graduação e ou questões curriculares em geral. Para tanto, o primeiro passo foi identificar, selecionar e recuperar os documentos. As palavras-chave utilizadas para a busca foram: formação de professores, formação docente, formação inicial, formação de educadores, formação de agentes, ambientalização curricular e o radical curric. Esse processo retornou pouco mais de seiscentas referências, dentre os 2.151 trabalhos que constavam no banco quando realizamos a busca, em 2012 e 2013.

Realizamos um processo de leitura e análise dos títulos e resumos dessas pesquisas, no intuito de selecionar os estudos cujo foco principal do processo investigativo fosse a inserção da temática ambiental em cursos de formação inicial. Após esse processo, foram selecionadas 85 dissertações e teses que compuseram o corpus documental desta pesquisa. Por questão de espaço neste artigo, as referências e resumos dos trabalhos podem ser encontrados em Rink (2014).

Uma ficha de análise e classificação foi criada para cada estudo e numerada sequencialmente, contendo título, resumo, palavras-chave, os dados institucionais, a classificação dos trabalhos pelo conjunto de descritores configurado para análise, além de observações gerais. A ficha contou com descritores da base institucional, englobando título, autor, orientador, ano da defesa, Instituição de Ensino Superior em que a obra foi defendida, estado, cidade, grau de titulação acadêmica e dependência administrativa. Também, contou com os seguintes descritores por nós denominados de base curricular-ambiental:

a) Modalidade do Curso: indicação do tipo de graduação (Bacharelado, Licenciatura, Tecnólogo).

b) Área Curricular: situa a área ou disciplina do currículo ou curso de graduação ao qual se vincula a pesquisa realizada. 
c) Tipo de Estudo: situa o tipo de estudo realizado pela pesquisa: diagnóstico de processos de ambientalização curricular (por exemplo, um estudo de caso); ou proposição, aplicação, avaliação de processos de ambientalização curricular; ou ensaio visando estabelecer fundamentos teórico-metodológicos para processos de ambientalização curricular.

d) Concepções de Educação Ambiental: conservacionista, pragmática ou crítica, conforme Layrargues e Lima (2014).

e) Concepções de Currículo: tradicional, crítica e pós-crítica conforme Silva (2004).

A análise e classificação das pesquisas foi realizada a partir da leitura dos títulos, resumos e dos textos integrais. Procuramos identificar indicativos trazidos pelo autor que nos permitissem realizar a análise e classificação em conformidade com os descritores estabelecidos. Desse modo, foram extraídos dos documentos elementos que permitiram a análise e categorização das dissertações e teses, em consonância com o referencial teórico adotado pelo nosso estudo. Os dados foram sistematizados com o uso de aplicativos específicos para edição de textos e planilhas eletrônicas, auxiliando na análise das tendências do conjunto de trabalhos.

Neste artigo, apresentamos alguns resultados obtidos com os descritores da base institucional para mostrar uma visão panorâmica da produção, concentrando-nos, de modo analítico-compreensivo, nos descritores da base curricular-ambiental.

\section{CARACTERÍSTICAS E TENDÊNCIAS DO CORPUS DOCUMENTAL}

Iniciamos a análise pelos descritores da base institucional. Embora a primeira dissertação ou tese defendida no Brasil no campo da EA date de 1981, trabalhos envolvendo a ambientalização curricular em cursos de licenciatura no Brasil foram localizados a partir de 1995, conforme indica a Figura 1.

Figura 1 - Distribuição Anual das 85 dissertações e teses

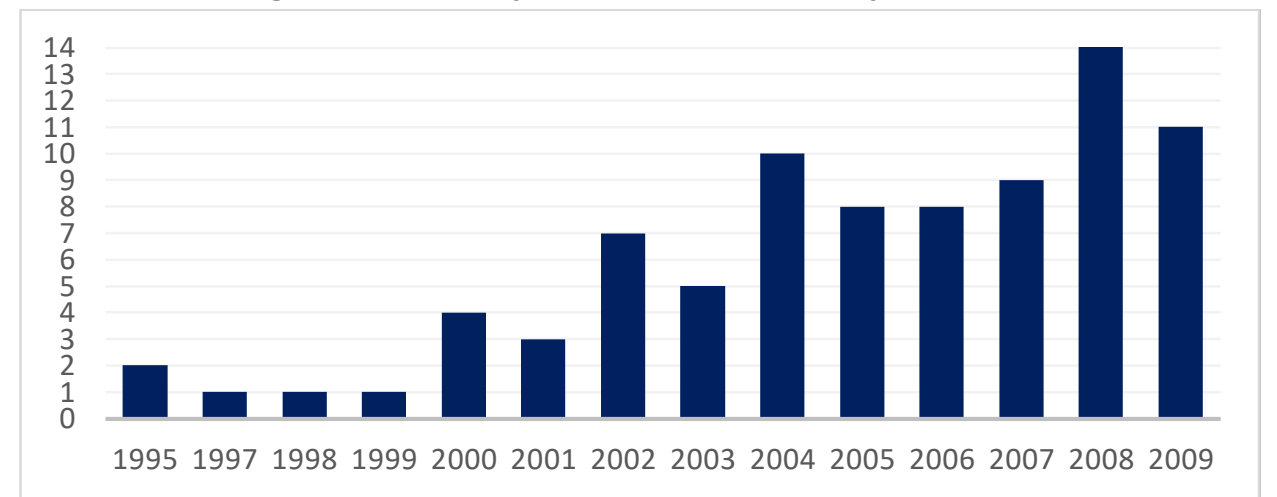

Fonte: Organizado por RINK, J. a partir do Banco de Teses do Projeto EArte (2019).

Notamos um crescimento após o ano 2000, sobretudo a partir de 2004. É possível que tal crescimento esteja ligado ao crescimento da Pós-Graduação nacional, às discussões suscitadas pela promulgação da Política Nacional de 
Educação Ambiental, em 1999, e pelos trabalhos da Rede ACES (início dos anos 2000), bem como às diversas conferências e eventos internacionais sobre a inserção da temática ambiental no âmbito universitário realizadas à época.

No conjunto de 85 trabalhos, houve predomínio de dissertações de mestrado acadêmico (sessenta trabalhos, perfazendo $70,5 \%$ do total) e onze estudos produzidos em programas de mestrado profissional (13\%), estes últimos defendidos a partir de 2002. Já as teses de doutorado representaram $16,5 \%$ da produção investigada (catorze trabalhos).

Em relação às IES em que os trabalhos foram defendidos, encontramos estudos em cinquenta instituições diferentes. Predominaram as IES de natureza pública, com $68,2 \%$ da produção, sendo $47 \%$ dos trabalhos defendidos em IES federais, $20 \%$ em IES estaduais e 1,2\% em instituição municipal. As IES particulares foram responsáveis por $31,8 \%$ de trabalhos. Dentre as cinquenta instituições produtoras, a Fundação Universidade do Rio Grande (FURG) foi responsável por sete trabalhos, a Universidade Estadual Paulista "Júlio de Mesquita Filho" (UNESP) por seis trabalhos, a Universidade de São Paulo (USP) e a Universidade Federal do Mato Grosso (UFMT), ambas com cinco trabalhos, e a Universidade Federal do Rio de Janeiro (UFRJ) por quatro trabalhos. As demais foram responsáveis por 1, 2 ou 3 trabalhos no conjunto de 85 dissertações e teses analisadas ${ }^{2}$.

Quanto aos descritores da base curricular-ambiental, na Modalidade do Curso, identificamos noventa cursos envolvidos, conforme Tabela 1. O total de classificações ultrapassa o total de 85 trabalhos, pois algumas pesquisas envolveram mais de uma modalidade de curso. As porcentagens foram calculadas sobre 85 documentos.

Tabela 1 - Distribuição das Modalidades de Curso abrangidas pelas 85 dissertações e teses

\begin{tabular}{|c|c|c|}
\hline Modalidade do curso & Número de Trabalhos & Percentual \\
\hline Licenciatura & 43 & $50,6 \%$ \\
\hline Bacharelado & 36 & $42,4 \%$ \\
\hline Tecnologia & 1 & $1,2 \%$ \\
\hline Não identificada & 10 & $11,8 \%$ \\
\hline Total & 90 & $106 \%$ \\
\hline
\end{tabular}

Fonte: Organizado por RINK, J. a partir do Banco de Teses do Projeto EArte (2019).

Notamos que houve predomínio de estudos que se deram no âmbito dos cursos de licenciatura (50,6\%). Dos 43 trabalhos que abordaram formação docente, catorze envolveram dois ou mais cursos, com destaque para as licenciaturas em Ciências Biológicas e Geografia, que aparecem, juntas, em oito pesquisas. Surpreendemo-nos positivamente com a quantidade de trabalhos desenvolvidos junto à formação de bacharéis, em $42,4 \%$ dos trabalhos. Encontramos, ainda, uma única dissertação que abordou dois cursos de tecnologia, ambos na área de Ciências do Ambiente. Vale comentar que também nos deparamos com cinco pesquisas que envolveram duas modalidades distintas, cursos de licenciatura e bacharelado de uma mesma universidade.

Dez pesquisas $(11,8 \%)$ não especificaram a modalidade do curso abrangida pelo estudo, tratando-se de dois ensaios teóricos e oito diagnósticos de situações e/ou processos de ambientalização curricular. Como não conseguimos obter os 
textos integrais dessas pesquisas, a análise dos resumos não forneceu elementos suficientes para classificação da modalidade investigada.

Em relação ao descritor Área Curricular, conforme mostrado na Figura 2, a área de Biologia foi abordada em trinta trabalhos (35,3\%), confirmando a grande aproximação entre EA e Biologia no contexto educacional formal. A articulação da EA com o currículo de Ensino de Ciências e/ou Biologia e a priorização de discussões dos problemas ambientais a partir de concepções biológicas é discutida também por Carvalho (2004) e Layrargues e Lima (2014).

Figura 2 - Distribuição por Área Curricular das 85 dissertações e teses

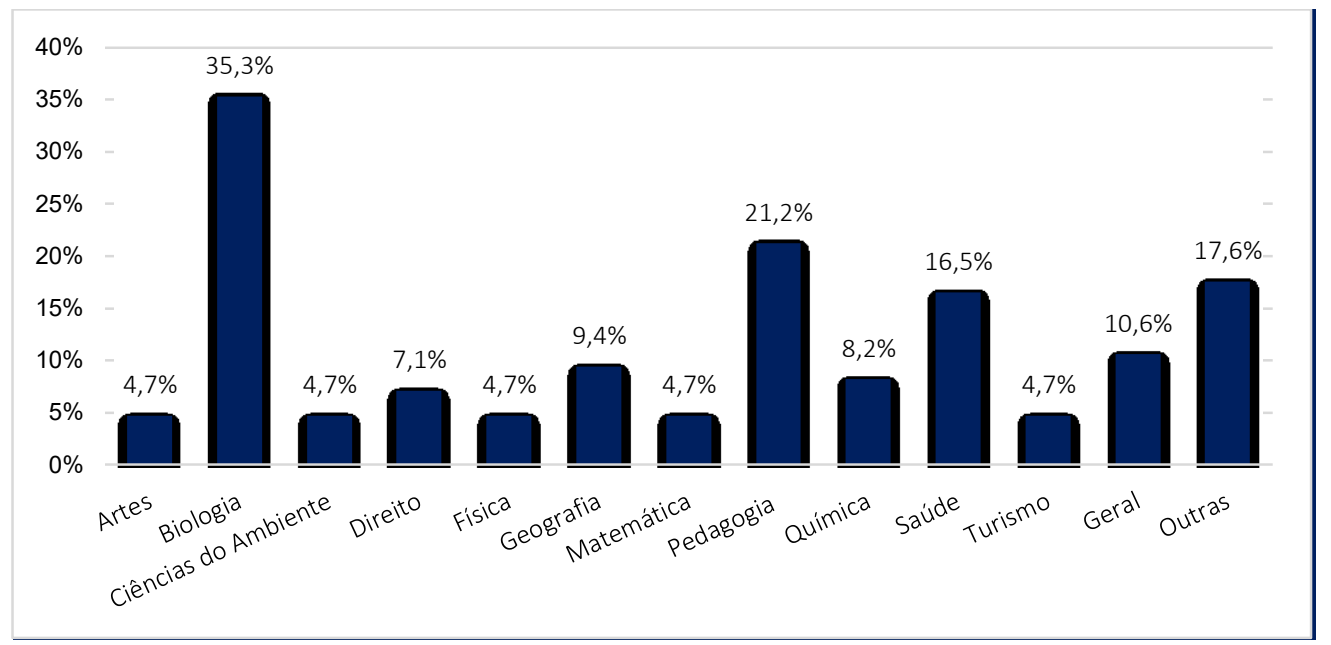

Fonte: Organizado por RINK, J. a partir do Banco de Teses do Projeto EArte (2019).

A área curricular Pedagogia conta com dezoito trabalhos (21,2\%). É possível afirmar que, desde os trabalhos da Rede ACES, no início dos anos 2000, diversas pesquisas que tratam da inserção da EA na formação inicial de pedagogos têm sido realizadas. Oliveira e Carvalho (2012) investigaram a incorporação da dimensão ambiental em projetos político-pedagógicos dos cursos de Pedagogia das universidades federais brasileiras e afirmaram que as questões ambientais têm ganhado espaço nas propostas curriculares e projetos dos cursos de Pedagogia, ainda que careçam de fundamentação mais articulada.

A terceira área mais presente foi Saúde (catorze estudos, 16,5\%), seguida por Geografia (oito trabalhos, 9,4\%); Química (sete pesquisas, 8,2\%); Direito (seis estudos, 7,1\%); Artes, Ciências do Ambiente, Física, Matemática e Turismo (quatro trabalhos cada, 4,7\%). Nove trabalhos foram classificados como Geral, por tratarem de fundamentos teórico-metodológicos para processos de ambientalização curricular sem, contudo, privilegiar uma determinada área ou, ainda, pelo fato de os resumos desses trabalhos abordarem a área curricular de modo genérico, não sendo possível obter os textos completos dos mesmos. Identificamos, ainda, quinze documentos $(17,6 \%)$ que abrangeram temas, tópicos ou conteúdos associados a demais áreas curriculares presentes em menor frequência dentro da produção investigada. Tais trabalhos foram agrupados na categoria Outras Áreas, e incluiu Carreira Militar, Economia, Filosofia, História, Letras e Sociologia (cada uma com um documento); Administração, Agronomia (dois documentos cada) e, por fim, Engenharia e Arquitetura e Urbanismo (três documentos cada). 
Passamos, agora, a analisar os resultados das classificações quanto aos descritores Tipo de Estudo, Concepção de EA e Concepção de Currículo. Nesses casos, houve necessidade da leitura do texto integral das dissertações e teses, pois os resumos dos trabalhos não traziam informações suficientes para as análises. Contudo, só conseguimos obter os textos integrais de 65 trabalhos do total de 85 do nosso corpus. O Projeto EArte possui um acervo da maioria das dissertações e teses disponíveis em sua base de dados, mas não da sua totalidade. Os trabalhos que não localizamos com a equipe do Projeto, tentamos obter em bibliotecas digitais de dissertações e teses, na internet de modo geral, ou por contato com os autores dos estudos. Mesmo com esses procedimentos, não conseguimos obter os textos completos de vinte trabalhos, razão pela qual nas análises seguintes lidamos com um corpus documental restrito, composto por 65 documentos.

Em relação ao descritor Tipo de Estudo, a maior parte das pesquisas (51 pesquisas, $78,4 \%$ de 65 documentos) consiste em estudos diagnósticos de cursos ou disciplinas. Predominam estudos que realizaram Diagnóstico de Cursos como um todo (47 documentos). Encontramos quatro estudos diagnósticos sobre uma disciplina em específico.

As pesquisas nesse contexto foram produzidas a partir dos anos 2000, e apresentaram crescimento ao longo do período aqui abrangido. Acreditamos que os documentos e encontros oficiais realizados nas décadas de 1980 e 1990, além de iniciativas como a Rede ACES, contribuíram para fomentar diagnósticos do grau de ambientalização curricular de cursos ou até de instituições, seja no âmbito nacional ou internacional. Essa constatação também é trazida nos trabalhos de Pavesi (2007); Farias (2008); Zuin, Farias e Freitas (2009); Peñagos (2012); Rodrigues (2013); Carvalho; Cavalari e Santos Silva (2015), entre outros.

No que se refere ao número expressivo de estudos diagnósticos dentro do nosso corpus documental, tais pesquisas visam descrever e avaliar iniciativas já existentes, evidenciar avanços, limites ou entraves eventualmente existentes nos processos de ambientalização curricular. Desse modo, conhecendo profundamente a realidade e seus fatores intervenientes, pode-se propor novas iniciativas e diferentes estratégias se necessário.

Em geral, entre os meios de coleta de dados usados pelos estudos diagnósticos de cursos, houve predomínio de entrevistas semiestruturadas, frequentemente realizadas com alunos e/ou docentes e, em alguns casos, também com coordenadores pedagógicos, diretores, alunos egressos e pesquisadores em EA. Em relação aos estudos que abrangeram a análise de uma ou mais disciplinas, muitas vezes as entrevistas serviram de ponto de partida para identificar disciplinas que, na visão dos discentes, abordaram a temática ambiental durante a graduação. Além das entrevistas, destacamos a análise de documentos oficiais realizada em boa parte das obras, com destaque para o Projeto Político Pedagógico (PPP) dos cursos, matrizes curriculares, planos de ensino e ementas.

Muitos dos estudos diagnósticos utilizaram diversos instrumentos de coleta de dados e de análise para averiguar a inserção da temática ambiental no curso, confrontando as informações das ementas, planos de ensino, projetos pedagógicos com declarações dos entrevistados. Acreditamos que essa diversidade de olhares favorece a elaboração de um diagnóstico mais detalhado, ao proporcionar contato com as múltiplas variáveis que podem influenciar nos 
processos de ambientalização curricular. Apesar de menos frequente, há estudos que se basearam numa única forma de coleta de dados (apenas a análise documental do PPP ou somente entrevistas com os docentes, por exemplo). Certamente, entendemos que os mecanismos de obtenção dos dados estão ligados diretamente aos objetivos pretendidos pelo autor e à proposta metodológica da pesquisa. Contudo, podem condicionar a análise do cenário investigado a uma única determinante dentro de uma realidade mais complexa.

Ainda em relação ao descritor Tipo de Estudo, dez estudos $(15,4 \%)$ fizeram proposição, aplicação e avaliação de cursos ou disciplinas. Correspondem a pesquisas com caráter de intervenção, voltadas para a inserção de aspectos de ambientalização no currículo dos cursos abrangidos, envolvendo a análise e avaliação das respectivas experiências.

Identificamos diversidade em relação às propostas. Encontramos uma proposta-ação de curso optativo de curta duração, um estudo sobre o desenvolvimento de oficinas para formação inicial docente e um projeto para oferta de disciplinas optativas em cursos de licenciaturas. Localizamos sete pesquisas que visaram realizar adequações teórico-metodológicas em disciplinas obrigatórias, existentes nas matrizes curriculares. Destacamos que três delas envolviam disciplinas de estágio supervisionado, tais como Prática de Ensino de Ciências e de Biologia, Estágio Supervisionado de Ciências para Biologia, Práticas de Ensino e Estágio Supervisionado de Física, proporcionando a discussão de conceitos e metodologias referentes à temática ambiental.

Apesar das particularidades dos trabalhos e das diferentes áreas curriculares e modalidades abordadas, pudemos identificar algumas aproximações. Seja através da reformulação de disciplinas obrigatórias, já existentes, ou por meio da criação de um novo espaço disciplinar optativo, a estrutura disciplinar foi o espaço encontrado para inserir a temática ambiental nos cursos. Assim, sinalizamos para a aparente pontualidade e isolamento de tais experiências dentro dos processos formativos investigados, pois não há indícios de que essas experiências foram incorporadas de modo permanente nos cursos envolvidos.

O terceiro grupo de trabalhos identificados em Tipo de Estudo reúne quatro estudos $(6,2 \%)$ que lidaram com fundamentos teórico-metodológicos para propostas e/ou programas. São três teses e uma dissertação que possuem caráter teórico, argumentativo e reflexivo e representam os trabalhos de natureza teórica, que buscam construir modelos explicativos de maior alcance, construindo diálogos e interlocuções com autores e campos disciplinares diversos, mesmo se referindo a experiências concretas (KAWASAKI; CARVALHO, 2009). Os aportes teóricos trazidos pelos documentos estabelecem diálogo entre a formação universitária, a EA e as diversas áreas do conhecimento. A menor incidência de ensaios teóricos na produção acadêmica em EA é apontada por Kawasaki et al. (2009) e Rosso et al. (2009). Vale salientar que concordamos com Kawasaki e Carvalho (2009) sobre o fato de que a busca pelo diálogo interdisciplinar é uma característica importante presente nesse tipo de estudo, pois contribui para a construção de identidades do campo da EA e para a consolidação da pesquisa nesse campo.

Passamos, agora, a tratar do descritor Concepções de Educação Ambiental presentes nos processos curriculares de incorporação das questões e temas ambientais em programas, cursos ou disciplinas na formação inicial docente, 
abordados pelas teses e dissertações que compõem nosso corpus documental. Reiteramos que foram adotadas como categorias para análise, nesse descritor, as macrotendências político-pedagógicas de Educação Ambiental propostas por Layrargues e Lima (2014): conservacionista, pragmática e crítica. A Tabela 2 apresenta a distribuição das classificações nesse descritor. 0 total de classificações ultrapassa o total de 65 trabalhos pois algumas pesquisas envolveram mais de uma macrotendência de EA. As porcentagens foram calculadas sobre 65 documentos.

Tabela 2 - Distribuição por Macrotendências de EA das 65 dissertações e teses

\begin{tabular}{|c|c|c|}
\hline Macrotendência de EA & Número de trabalhos & Percentual \\
\hline Conservacionista & 37 & $56,9 \%$ \\
\hline Pragmática & 24 & $36,9 \%$ \\
\hline Crítica & 21 & $32,3 \%$ \\
\hline Não identificada & 2 & $3,1 \%$ \\
\hline Total & 84 & $129,2 \%$ \\
\hline
\end{tabular}

Fonte: Organizado por RINK, J. a partir do Banco de Teses do Projeto EArte (2019).

Predominam estudos ligados à macrotendência conservacionista de EA. É importante reforçar que não condenamos a inserção de conteúdos ligados à Ecologia e Ciências do Ambiente em processos de ambientalização curricular, principalmente nas áreas de formação que guardam menor proximidade com a área ambiental. Todavia, conforme os referenciais da Rede ACES, é preciso incorporar as várias dimensões da temática ambiental em tais processos curriculares (GELI; JUNYENT; SÁNCHEZ, 2003). Assim, não negamos a importância dos processos biológicos e leis físicas para a temática ambiental, mas não podemos reduzi-la a tais dimensões, sendo assim, deslocamos nossos olhares de um mundo estritamente biológico para integrar as humanidades, os movimentos sociais, a cultura, passando a uma visão complexa de ambiente.

Um dos elementos comuns nesses trabalhos é a análise positiva para a existência de disciplinas ou outros espaços que tratam de conteúdos ambientais na formação dos profissionais, mesmo que em perspectiva ecologizante e conservadora, já que, frente a um cenário de omissão, seriam indicadores do início de um processo mais amplo de ambientalização desses cursos.

Um olhar semelhante foi encontrado em alguns estudos que investigaram cursos de Licenciatura em Pedagogia. Pudemos apreender que questões como resíduos sólidos, desmatamento, poluição e outros problemas ambientais são discutidos, quase que exclusivamente, pelo viés ecológico e conservacionista na formação de pedagogos; seja em disciplina específica (como Educação Ambiental ou Metodologia do Ensino de Ciências) ou em seminários, encontros e oficinas. Essa realidade está presente, também, nas Licenciaturas em Ciências Biológicas, sendo que muitas das pesquisas retratam que a temática ambiental é ligada exclusivamente à Ecologia, sendo raras as ligações com outras áreas dentro da Biologia ou fora dela. A análise de alguns desses estudos revela o caráter naturalista, inclusive, nos Projetos Político Pedagógicos e demais documentos oficiais dos respectivos cursos.

Tais resultados ilustram a estratégia mais comum adotada pelas universidades de somar conteúdos ou inserir disciplinas aos currículos existentes (RIOJAS, 2003). Para esse autor, isso não ocasiona mudanças no funcionamento e lógica delas, 
acabando por contribuir para a fragmentação da temática ambiental no âmbito universitário.

Prosseguindo com a discussão do descritor Concepções de EA, em 24 documentos $(36,9 \%)$, as características de ambientalização curricular retratadas pelas pesquisas foram consideradas como alinhadas à macrotendência pragmática de EA, sendo 23 estudos diagnósticos e um que retrata a proposta e efetivação de uma disciplina em particular. Grosso modo, indicam que a presença de conteúdos ambientais na disciplina ou curso é suficiente para ambientalizar o curso e, consequentemente, formar profissionais com consciência crítica e aptos a lidar com a problemática ambiental em seu fazer cotidiano. Outro ponto em comum foi a perspectiva utilitária de ambiente encontrada nas situações investigadas. Tal perspectiva considera o ambiente natural como um recurso e compreende que a preservação dos elementos bióticos e abióticos se torna um imperativo na busca do desenvolvimento sustentável e da sobrevivência das gerações futuras humanas (LAYRARGUES; LIMA, 2014). Embora essa perspectiva se afaste da dimensão puramente ecológica e conservacionista e se aproxime das esferas do consumo e da produção, ainda há ausência da dimensão social, política, econômica e cultural ao considerar o ambiente e a EA.

A análise dos documentos classificados na macrotendência pragmática nos leva a acreditar que a inserção da temática ambiental se dá, portanto, de modo a capacitar ou dotar o aluno de informações e conhecimentos considerados válidos para a atuação profissional, já que a gravidade do panorama socioambiental exige medidas práticas, efetivas e rápidas por parte dos mesmos. São privilegiados processos formativos de caráter tecnicista, com objetivo de preparar os futuros profissionais aparelhados com as demandas do mercado de trabalho nas áreas supracitadas. Os conteúdos ambientais são considerados importantes para capacitar o docente a lidar com a temática na educação básica, na perspectiva de instrumentalizá-lo para o exercício da profissão.

O último grupo considerado nesse descritor é composto por 21 trabalhos $(32,3 \%)$ que envolvem proposição/investigação de processos de ambientalização curricular na perspectiva da macrotendência crítica de EA. Encontramos nove estudos diagnósticos, sobretudo pesquisas que investigaram dois ou mais cursos e analisaram diversas disciplinas dentro deles, oito propostas de intervenção em cursos e/ou disciplinas e quatro estudos com natureza teórica.

Ressaltamos que esses 21 trabalhos não encerram a EA crítica de modo monolítico e homogêneo. Observamos diferentes elementos em consonância com a macrotendência crítica de EA, em maior ou menor predominância ao longo das análises. Dentro de suas especificidades, os processos de ambientalização curricular tratados nessas 21 dissertações e teses constituem aproximações a "uma dimensão ético-política transformadora para as práticas educativas, de maneira a influir na forma como as atuais e futuras gerações se relacionam com a natureza e com os demais sujeitos sociais" (TREIN, 2012, p.311).

Pudemos inferir, a partir de nossas análises, que os estudos ambientalizados empreendidos por tais pesquisas pautam-se por uma concepção de ambiente integrado, multidisciplinar e interdependente, seja na proposta de curso ou disciplina como um todo, nos fundamentos teóricos assumidos e referenciados pelos autores em trabalhos de natureza teórica ou ainda em uma ou mais 
disciplinas analisadas pelas pesquisas. Desse modo, a abordagem da temática ambiental considera o ser humano como integrante da natureza, não o dissociando da mesma e não reduzindo sua presença a mero utilizador dos recursos ou a agente degradador do ambiente.

Considerando as pesquisas do subgrupo, que planejaram e desenvolveram propostas para a inserção da temática ambiental em contexto de formação inicial, identificamos que todas utilizaram como estratégia político-metodológica o trabalho coletivo, o que, para Tonso (2010), é característica importante para a EA crítica. Admitimos, todavia, que, embora seja uma condição necessária para a EA crítica, por si só pode não ser suficiente para tanto. Em alguns casos, houve forte presença de metodologias participativas e de resolução de problemas nas propostas, embora com enfoques diferenciados.

A existência de metodologias participativas, envolvendo trabalhos coletivos, também foi evidenciada em estudos diagnósticos desse subgrupo que investigaram diversas disciplinas de um ou vários cursos. Relembramos que a realidade heterogênea dos casos nos levou, muitas vezes, a classificá-los em mais de uma macrotendência, de acordo com os indícios presentes nos trabalhos. Em todas essas pesquisas os autores revelam a existência de uma ou mais disciplinas nos cursos investigados que apresentam forte incentivo às estratégias coletivas de trabalho, alinhadas à visão crítica de EA dentro do curso. Assim, mesmo que os cursos possuam disciplinas com viés conservador e/ou pragmático, houve iniciativas e espaços para abordagem da EA crítica. Nesse sentido, a adequação metodológica, contemplando metodologias participativas, também é indicativo para estudos ambientalizados, já que refletem a preocupação com a abertura de espaços de reflexão e participação democrática na Educação Superior (CARVALHO; CAVALARI; SANTANA, 2003).

Para Carvalho (2010), há necessidade de aprofundar os debates entre os pesquisadores de EA a respeito da relação estreita entre a EA e os processos de transformação social, o que nem sempre é subsidiado por fundamentos teóricos. Para o autor, isso reforçaria o risco de posturas utilitárias e pragmáticas nas investigações e práticas de EA. Assim, um aspecto positivo dos trabalhos desse subgrupo foi o forte estímulo à superação da visão ingênua dos futuros docentes sobre a problemática ambiental e frequentes práticas comportamentalistas.

Nos trabalhos que envolveram licenciaturas, encontramos preocupação em contextualizar e problematizar o campo em que se insere o curso e o cotidiano dos alunos. Procuram discutir a inserção da EA na formação dos professores aliada à preocupação com as dimensões éticas e políticas, corroborando o que Carvalho (2004) aponta como a formação de um sentido de responsabilidade ética e social na formação docente. Tais pesquisas indicam que os processos de formação desenvolvidos não têm como foco a formação estritamente comportamentalista dos envolvidos (alunos e/ou professores, gestores entre outros) e defendem a busca de mecanismos para que tais profissionais tenham, incutida já na formação inicial, uma postura coletiva e reflexiva diante da complexidade da problemática ambiental, apresentando importante elemento da EA crítica - a "negação da perspectiva utilitária" (TONSO, 2010, p. 10).

No que diz respeito às nossas análises, seja em uma proposta de formação 
nas pesquisas esse elemento em destaque nas discussões de leituras propostas aos discentes, execução de seminários, dinâmicas de grupo, planos de ensino formulados para o estágio supervisionado, questões norteadoras para construção de memorial formativo, entre outros. Assim, a despeito do caráter da disciplina proposta (obrigatória ou optativa) e do curso e áreas curriculares contemplados, os estudos levaram em conta a complexidade da questão ambiental na formação inicial e a projetaram nas atividades, de modo superficial ou em profundidade, ultrapassando a abordagem conservadora e/ou utilitária da dimensão ambiental.

Destacamos, também, o caráter integrador presente em parte das situações enfocadas pelas 21 pesquisas que evidenciaram uma perspectiva de EA crítica nos processos de ambientalização curricular investigados. Para Tonso (2010), a tendência a um pensamento integrador é um indicador para uma EA crítica, que se manifesta no esforço de articular os vários saberes que norteiam o entendimento da realidade e o rompimento com a hierarquização e fragmentação do conhecimento. Encontramos referência a disciplinas como Atividades Integradas ou Interdisciplinares, nas quais há a realização de debates, trabalhos de campo e construção de projetos interdisciplinares, tendo a temática ambiental como cerne, muitas vezes, propondo conexões com outras disciplinas. Na mesma linha, há pesquisas que revelam a existência de projetos integradores, que possuem espaço na matriz curricular dos cursos com carga horária definida e proporcionam o planejamento e execução de atividades teórico-práticas.

Outra constatação ocorreu através do olhar para os referenciais de EA presentes nas pesquisas do subgrupo que fez proposição, aplicação e avaliação de cursos ou disciplinas. Todas se apropriam de referenciais ligados à macrotendência crítica de EA, na perspectiva dos estudos de Marcos Reigota, Mauro Guimarães, Mauro Grün, Philippe P. Layrargues, Gustavo Lima e Carlos F. Loureiro; seja nos capítulos teóricos, nas análises de concepções de alunos, de professores, de coordenadores de cursos e de documentos oficiais.

Por outro lado, notamos que, algumas vezes, as práticas desenvolvidas acabaram tendo perspectivas e abordagens pedagógicas conservadoras ou pragmáticas, e não corresponderam plenamente ao posicionamento teóricocrítico assumido pelos trabalhos. São exemplos a elaboração de propostas e de atividades partindo dos docentes, sem envolvimento dos estudantes em processos de investigação-reflexão críticos; metodologias pouco participativas; propostas avaliativas classificatórias, hierárquicas e determinadas pelos professores; ausência de espaços colaborativos nas disciplinas e cursos, sem vínculo com as questões cotidianas e realidade local dos estudantes. Desse modo, inferimos certo distanciamento entre o discurso e a prática relatada. Sem dúvida, são muitos os obstáculos enfrentados na implementação de processos de ambientalização curricular numa perspectiva crítico-emancipatória. Junta e Santana (2009) também sinalizam para a existência de muitas pesquisas que se apropriam de aportes teóricos críticos, mas que realizam abordagens conservadoras de EA. Conforme Fracalanza (2006), essa situação revela um distanciamento entre o nível de propósito e o nível de fato presentes em muitas pesquisas acadêmicas.

Retomamos Layrargues e Lima (2014, p. 32), ao afirmarem que as tendências conservacionista e pragmática são "dois momentos de uma única linhagem de pensamento que foi sendo ajustada conforme as demandas neoliberais da atualidade", não possuindo a intenção de promover transformação nos 
pensamentos e ações dos indivíduos. Nesse sentido, a produção investigada encerra o predomínio de macrotendências não críticas de EA. Além disso, nos processos de ambientalização curricular em que evidenciamos a vertente da EA crítica, foi notório o caráter teórico e somente prognóstico.

Agora, discutiremos os resultados frente ao descritor Concepção de Currículo. Uma constatação inicial é a de que raros são os trabalhos que trazem referenciais do campo do currículo, ainda que todos teçam, de modo pleno ou ao menos significativo, discussões sobre questões curriculares. Em geral, as dissertações e teses buscam situar o curso investigado no âmbito das diretrizes curriculares e dos marcos regulatórios da EA. Isso é um dado preocupante, já que partimos do pressuposto de que estudos sobre ambientalização curricular situam-se no campo do currículo tal como consideram Kitzmann (2009), Farias (2008) e Pavesi (2007) e outros autores, os quais destacam a importância do aporte teórico da área de currículo para os estudos sobre o tema. Assumimos que o currículo é um artefato cultural e uma construção social, sendo impossível ser compreendido sem analisar as relações e os contextos que o determinam (SILVA, 2004) e, por isso, os estudos sobre a ambientalização dos currículos em cursos de graduação, ainda que predominantemente propositivos, deveriam resgatar referenciais sobre concepções e determinantes de análise curricular. Tais referenciais serviriam de indícios para a análise dos processos de ambientalização curricular retratados pelas pesquisas.

Nas dissertações e teses em que identificamos referenciais teóricos sobre currículo, frequentemente, há o aporte das Teorias Críticas e Pós-Críticas (SILVA, 2004), representadas por autores como Apple, Althusser, Giroux e Sacristán. Os trabalhos, no geral, tecem críticas à estruturação curricular tradicional vigente na Educação Superior brasileira, apontam a distância entre os referenciais e a realidade universitária e discutem as situações investigadas partindo de um olhar para questões culturais, étnicas e sociais relacionadas à temática ambiental, consideradas importantes na formação profissional e muitas vezes negligenciadas pelo caráter mais técnico dos cursos de graduação.

Utilizamos a categorização de Silva (2004), que classifica as teorias de currículo em tradicionais, críticas e pós-críticas.

A concepção tradicional de currículo esteve presente em 61 trabalhos (93,8\% dos 65 documentos). Na quase totalidade dos estudos, deparamo-nos com elementos que possibilitam entender o currículo enquanto expressão de disciplinas, privilegiando aspectos teóricos das mesmas, com foco nos conteúdos de Ecologia e Ciências Ambientais como um todo, trabalhando-os de forma pontual e fragmentada. A realidade expressa na maioria das pesquisas indica que o conhecimento da temática ambiental e da EA é importante para a Educação Superior, mas ocupa espaço curricular próprio, sendo ministrada por um docente específico ou por um conjunto de docentes com formação voltada para a temática ambiental. Nesse sentido, confirmam o que Pereira e Cortelazzo (2003) comentam sobre a análise dos currículos universitários nacionais demonstrar uma estrutura fechada, instrumental e pouco flexível.

Identificamos, ainda, que os processos de ambientalização curricular desvelados pelo conjunto das dissertações e teses se mostram fortemente alinhados à perspectiva de elenco de conteúdos, necessários para que o 
profissional em formação saiba lidar com a problemática ambiental em seu campo de atuação. Excetuando-se as pesquisas de natureza teórica, os demais estudos trazem situações em que ocorreu a incorporação de temáticas relativas ao ambiente, seja em disciplinas obrigatórias ou optativas.

A partir do olhar panorâmico para as obras, percebemos que a inserção de conteúdos ambientais aconteceu (ou foi incentivada) no curso pesquisado como forma de capacitar o egresso. Implicitamente, entendemos que os conteúdos e saberes ambientais seriam resposta direta à questão: o que os futuros profissionais dessa área precisam saber sobre as questões ambientais? Poluição, logística reversa e outros temas se fazem presentes, enquanto conceitos como justiça ambiental são raramente citados. Isso evidencia uma visão restritiva para a questão, a partir da preconização e seleção de alguns temas ambientais em detrimento a outros. Não nos surpreende, portanto, que a maioria das obras analisadas revelem uma concepção de EA conservacionista e/ou pragmática. É indiscutível a importância de ambientalizar a Educação Superior, mas tal processo não deve ser pautado em discursos pragmáticos e utilitários, visando unicamente a formação profissional para o mercado de trabalho.

Para Gesser e Ranghetti (2011), a flexibilização curricular é um dos princípios epistemológicos essenciais que devem ser considerados para repensar o currículo da Educação Superior. Lembramos que a flexibilidade também é indicativa de um estudo ambientalizado, conforme referencial da Rede ACES (JUNYENT; GELI; ARBAT, 2003). Infelizmente, a quase totalidade da produção aqui investigada desvela acentuada rigidez e compartimentalização na estrutura dos cursos, de modo geral. A forma como são organizados não proporciona ao aluno o direcionamento de seu processo formativo, com raras oportunidades de escolha para o discente em relação às disciplinas optativas.

Mais raras ainda são situações nas quais o aluno pode/deve obter créditos em outros institutos/cursos da IES, conferindo maior versatilidade em sua formação. Segundo Pereira (2010), seriam espaços importantes pois indicam o entendimento de que a formação acadêmica extrapola as disciplinas, incorporando novas formas de aprendizagem e saberes. A temática ambiental é favorecida, possibilitando trabalhos interdisciplinares e com viés prático, já que revelam "níveis de abertura do currículo para interações entre disciplinas, atividades extra-classe e até mesmo entre diferentes cursos" (CARVALHO; CAVALARI; SANTANA, 2003, p. 122).

Identificamos apenas três trabalhos alinhados à concepção crítica de currículo. Todos realizaram discussões de natureza teórica, portanto foram classificados como fundamentos teórico-metodológicos para propostas e/ou programas. Neles, o tratamento da temática ambiental na Educação Superior está vinculado à ideia de que o currículo é uma construção social e que não pode ser compreendido sem que sejam analisadas as relações de poder que o determina (SILVA, 2004). Tais estudos situam o currículo como artefato de lutas e conflitos, e se preocupam em discutir o papel da universidade e do curso ou área curricular, o perfil de seus estudantes e dos futuros profissionais, professores, dirigentes e, em alguns casos, até mesmo a comunidade de entorno. Ressaltam as desigualdades existentes, alertando para que os contextos formativos despertem para as interrelações entre poder, identidade e saberes ambientais. 
Por fim, um único estudo avançou em direção à discussão alinhada à concepção pós-crítica de currículo, discutindo a diversidade cultural no âmbito universitário, consagrando-a como espaço privilegiado para o desenvolvimento da EA crítica. Além disso, o ensaio discute os vínculos entre as políticas curriculares para ambientalização curricular da Educação Superior e a EA na formação profissional aliada às questões de inclusão, gênero, sexualidade e etnias, por exemplo, na perspectiva de que não podem ser reduzidas à dinâmica de classes e relações de poder, assumindo assim uma perspectiva das teorias críticas. A esse respeito, Morales et al. (2010) apontam um crescimento de estudos que tentam fortalecer a inter-relação entre EA e as teorias pós-críticas do currículo, pois ambos os campos precisam ser conhecidos e dinamizados pelos profissionais educadores ambientais. Todavia, em nosso corpus documental isto não se efetivou. A abordagem pós-crítica de currículo pode estar ocorrendo em outras pesquisas no campo da EA com recorte distinto do assumido neste estudo, bem como em anos posteriores podem ter surgido trabalhos com tal abordagem curricular, algo que seria interessante investigar em pesquisas complementares a esta.

\section{CONSIDERAÇÕES FINAIS}

Entendemos que pesquisas do tipo estado da arte em EA são essenciais para a socialização da pesquisa em EA, possibilitando identificar e explicitar os percursos da produção acadêmica sobre o tema, explicitar suas bases teóricas, epistemológicas, metodológicas, a historicidade da pesquisa em EA no país e, ainda, as características, tendências e lacunas da produção. Analisamos um conjunto de pesquisas disponíveis no Banco de Teses e Dissertações do EArte, que tratou de programas ou cursos de formação inicial de professores e profissionais educadores ambientais na Educação Superior, avaliando a perspectiva de ambientalização curricular dessas pesquisas.

Identificamos 85 dissertações e teses dentro do tema de interesse, defendidas entre 1981 e 2009. Essa produção é composta, majoritariamente, de estudos diagnósticos de cursos de licenciatura, predominando os cursos de Biologia e Pedagogia. No que concerne à concepção de EA, a maioria se posiciona na macrotendência conservacionista, seguida da perspectiva pragmática. Predominaram, portanto, perspectivas não críticas de EA nos processos de ambientalização curricular propostos e/ou investigados. No recorte temporal considerado, os trabalhos segundo o viés crítico de EA apresentam pequeno crescimento a partir dos anos 2000 . No contexto da EA crítica, encontramos certo distanciamento entre o nível de propósito e o nível de fato apresentado pelas pesquisas, notadamente por assumirem referenciais críticos de EA, mas cujas propostas não se alinham com essa perspectiva. No que tange à concepção de currículo, a perspectiva tradicional foi encontrada majoritariamente nas pesquisas, enquanto as tendências críticas e pós-críticas estiveram restritas a trabalhos de caráter teórico.

Nossa investigação indicou forte tendência à disciplinarização da temática ambiental nos cursos de formação inicial docente. De certo modo, consideramos isto válido, pois sinaliza para tentativas de superar o conjunto de limitações até aqui discutido. Porém, devemos tentar superar essa disciplinarização e promover processos de ambientalização mais críticos e reflexivos e que englobem todo o 
currículo de formação. Entendemos que ir além da disciplinarização passe pela superação dos diversos entraves ligados aos condicionantes institucionais desvelados pelos trabalhos, que, certamente, podem favorecer abordagens superficiais, com viés técnico e com perspectivas conservacionista e pragmática de $E A$, dificultando o alcance de uma perspectiva crítica nessa formação.

Também, admitimos que a ambientalização dos currículos universitários não é um fenômeno unilateral e com definição acabada. É um processo que depende de contextos amplos e, ao mesmo tempo, restritos. Depende, igualmente, de espaços para a produção dos currículos, estando sujeito às multiplicidades de discursos, tal como apontam os trabalhos da Rede ACES.

Sabemos que a pesquisa em EA no Brasil é relativamente recente e que os estudos de ambientalização curricular emergem em um cenário cujas bases epistemológicas encontram-se em construção. Nesse sentido, a luta por espaço para incorporar a temática ambiental (e a própria EA) nas universidades é uma realidade que reflete na produção acadêmica nacional sobre o tema.

Embora seja um retrato parcial da produção acadêmica nacional voltada para a temática, esperamos que este trabalho contribua para ampliar a divulgação do conhecimento gerado na área e suscite elementos para novas investigações referentes à pesquisa em EA e aos processos de ambientalização curricular. 


\title{
Curricular greening in highereducation: characteristics and trends of brazilian dissertations and theses (1987-2009)
}

\begin{abstract}
This research integrated an interinstitutional project of identification, analysis and evaluation of Brazilian dissertations and theses in Environmental Education (EE) defended in the period 1987-2009 (Projeto EArte) and we addressed the following question: what concepts and practices of curricular greening can be observed in the dissertations and EE theses aimed at training environmental teachers and educators? Our goal was to analyze the curricular greening processes proposed and / or studied by these dissertations and theses. The survey of documents was carried out with the Bank of Theses of the EArte Project, whose data were obtained from the Bank of Theses of Capes and other sources of information of the Brazilian scientific production. 85 dissertations and theses were identified with respect to the theme of this research, from a universe of 2,151 research works in AE produced within the scope of Brazilian postgraduate studies until 2009. In addition to the production scenario (year of defense, producing institutions, degree of degree) academic among other aspects), the documents were analyzed in relation to the following curricular-environmental descriptors: modality of the degree course; curricular area, type of study; conception of environmental education; and curriculum design. Among the results, we highlight that the works predominantly cover degrees in Biological Sciences and Pedagogy; most of them developed curricular diagnosis of specific courses and / or disciplines, with little research implementing and evaluating curricular greening proposals; most of the processes investigated by the works bring non-critical perspectives on $\mathrm{EE}$, linked to conservationist and pragmatic trends; there is an incipient presence from the perspective of critical EE in the set of documents, albeit in a prognostic and theoretical way. The study also indicated the persistence of the debate about turning the environmental theme into subjects in the initial training of teachers and educators and pointed to several institutional conditions that favor restricted and specific curricular greening processes.
\end{abstract}

KEYWORDS: Curricular Greening. Educational Research. Environmental Education. Higher Education. 


\section{NOTAS}

1 Este artigo se refere ao recorte temporal investigado originalmente por ocasião da pesquisa de Rink (2014), abrangendo os dados disponíveis à época e compreendendo o período 1981-2009.

2 Uma análise mais ampla da base institucional foi apresentada, preliminarmente, em evento acadêmico nacional realizado em 2013.

\section{REFERÊNCIAS}

ANDRÉ, M. A produção acadêmica sobre formação de professores: Um estudo comparativo das dissertações e teses defendidas nos anos 1990 e 2000. Revista Brasileira de Pesquisa sobre Formação Docente, Belo Horizonte, v. 1, n. 1, p. 41$56,2009$.

BRASIL. Ministério da Educação. Conselho Nacional de Educação. Diretrizes Curriculares Nacionais para a Educação Ambiental. Resolução CNE no 2, de 15 de junho de 2012. Brasília: MEC/CNE, 2012.

CARIDE GÓMEZ, J. A. La Educación Ambiental en las Universidades y la enseñanza superior: viejas y nuevas perspectivas para la acción en clave de futuro. In: CONGRESO IBEROAMERICANO DE EDUCACIÓN AMBIENTAL, 5., 2007, Joinville. Anais [...] Programa de las Naciones Unidas para el Medio Ambiente, 2007. p. 429-442.

CARVALHO, I. C. M. Educação ambiental: a formação do sujeito ecológico. São Paulo: Cortez, 2004.

CARVALHO, L. M. Que educação ambiental desejamos? Revista Ciências em Foco, Campinas, v. 1, n. 3, p. 1-22, 2010.

CARVALHO, L. M.; CAVALARI, R. M. F.; SANTANA, L. C. Características de um estudo ambientalizado - a experiência do campus da Unesp Rio Claro-SP-Brasil. In: JUNYENT, M. E.; GELI, A.M.; ARBAT, E. (Orgs.). Ambientalización Curricular de los Estudios Superiores: proceso de caracterización de la Ambientalización Curricular de los Estudios Universitarios 2. Girona: Universitat de Girona/Servei de Publicaciones, 2003, p. 117-124.

CARVALHO, L. M.; CAVALARI, R. M. F.; SANTOS SILVA, D. dos. Ambientalização nas instituições de Ensino Superior: as teses e dissertações em Educação Ambiental desenvolvidas no Brasil. In: GUERRA, A. F.S. (Org.). Ambientalização e sustentabilidade nas universidades: subsídios, reflexões e aprendizagens. Itajaí: Ed. da Univale, 2015. p. 47-65.

FARIAS, C. R. O. A produção da política curricular nacional para a Educação Superior diante do acontecimento ambiental: problematizações e desafios. 2008. 214 f. Tese (Doutorado em Educação) - Universidade Federal de São Carlos, São Carlos, 2008. 
FRACALANZA, H. O ensino de Ciências no Brasil: livros didáticos $\mathrm{X}$ projetos de ensino. In: FRACALANZA, H.; MEGID NETO, J. (Orgs.). O livro didático de Ciências no Brasil. Campinas: Komedi, 2006. p. 125-152.

GAY, L. Educational research: competencies for analysis \& aplication. Columbus: Charles E. Merril Publishing, Bell \& Howell, 1981.

GELI, A. M.; JUNYENT, M. E.; SÁNCHEZ, S. (Orgs.). Ambientalización Curricular de los Estúdios Superiores: diagnóstico de la Ambientalización Curricular de los Estudios Superiores 3. Girona: Universitat de Girona/Servei de Publicaciones, 2003.

GESSER, V.; RANGHETTI, D. S. O currículo no ensino superior: princípios epistemológicos para um design contemporâneo. Revista e-curriculum, São Paulo, v. 7, n. 2, p. 1-23, ago. 2011.

HERREMANS, I.; ALLWRIGHT, D. E. Environmental management systems at North American universities: What drives good performance? International Journal of Sustainability in Higher Education, Bradford, v. 1, n. 2, p. 168-181, 2000.

JUNTA, V.S.; SANTANA, L.C. Concepções de educação ambiental e suas abordagens políticas: análise dos trabalhos dos Encontros de Pesquisa em Educação Ambiental (I, II, III EPEAS). In: Encontro de Pesquisa em Educação Ambiental, 5. 2009, São Carlos. Anais [...] São Carlos, 2009. p. 1-15. Disponível em: http://www.epea.tmp.br/epea2009_anais/welcome/. Acesso em: 15 mai. 2019.

JUNYENT, M. E.; GELI, A.M.; ARBAT, E. (Orgs.). Ambientalización Curricular de los Estudios Superiores: proceso de caracterización de la Ambientalización Curricular de los Estudios Universitarios 2. Girona: Universitat de Girona/Servei de Publicaciones, 2003.

KAWASAKI, C. S.; CARVALHO, L. M. Tendências da pesquisa em Educação Ambiental. Educ. rev, Belo Horizonte, v. 25, n. 3, p. 143-157, dez. 2009.

KAWASAKI, C. S. et al. A pesquisa em educação ambiental nos ENPECs: contextos educacionais e focos temáticos. In: ENCONTRO NACIONAL DE PESQUISA EM EDUCAÇÃO E CIÊNCIAS, 7., 2009, Florianópolis. Atas [...] Florianópolis: UFSC, 2009. p. 1-12.

KITZMANN, D. I. S. Ambientalização sistêmica na gestão e na educação ambiental: estudo de caso com o Ensino Profissional Marítimo - EPM. 2009. 239 f. Tese (Doutorado em Educação Ambiental) - Universidade Federal de Rio Grande, Rio Grande, 2009.

LAYRARGUES, P. P.; LIMA, G. F. C. As macrotendências político-pedagógicas da educação ambiental brasileira. Ambiente \& Sociedade, Campinas, v. 17, n. 1, p. 23-40, 2014. 
MARCOTE, P. V.; SUÁREZ, P. A. Planteamiento de un marco teórico para la Educación Ambiental para un desarrollo sostenible. Revista Electrónica de Enseñanza de las Ciencias, s/l, v. 4, n. 1, p. 1-16, 2005.

McCORMICK, J. Rumo ao paraíso: a história do movimento ambientalista. Rio de Janeiro: Relume-Dumará, 1992. 224 p.

MEGID NETO, J. Educação Ambiental como campo de conhecimento: a contribuição das pesquisas acadêmicas para sua consolidação no Brasil. Pesquisa em Educação Ambiental, Unesp-UFSCar-USP, v. 4, n. 2, p. 95-110, jan. 2009.

MORALES, A. G. M. et al. Educação ambiental e multiculturalismo: reflexões para formação de educadores. Práxis Educativa, Ponta Grossa, v. 5, n. 1, p. 31-38, jan./jun. 2010.

OLIVEIRA, M. G.; CARVALHO, L.M. Os projetos político-pedagógicos dos cursos de Pedagogia e os temas ambientais: o caso das universidades federais brasileiras. Perspectiva, Florianópolis, v. 30, n. 2, p. 445-472, ago., 2012.

PAVESI, A. A ambientalização da formação do arquiteto: o caso do Curso de Arquitetura da Escola de Engenharia de São Carlos (CAU, EESC-USP). 2007. 199 f. Tese (Doutorado em Educação) - Universidade Federal de São Carlos, São Carlos, 2007.

PEÑAGOS, W. M. M. Ambientalización curricular en la educación superior: un estudio cualitativo de las ideas del profesorado. In: España Profesorado. Revista de Currículo y Formación del Profesorado, Granada, v. 16, n. 2, p. 77-103, 2012.

PEREIRA, E. M. de A. Universidade e Currículo: perspectivas de Educação Geral. São Paulo: Mercado de Letras, 2010.

PEREIRA, E. M. A. P; CORTELAZZO A. L. Flexibilização Curricular: uma experiência institucional. Revista Avaliação, Campinas, v. 7, n. 4, p. 115-128, 2003.

RINK, J. Ambientalização curricular na Educação Superior: tendências reveladas pela pesquisa acadêmica brasileira (1987-2009). 2014. 262 f. Tese (Doutorado em Educação) - Faculdade de Educação, Universidade Estadual de Campinas, Campinas, 2014.

RIOJAS, J. A complexidade ambiental na universidade. In: LEFF, E. (Org.). A complexidade ambiental. São Paulo: Cortez, 2003. p. 217-240.

RODRIGUES, C. A ambientalização curricular da educação física nos contextos da pesquisa acadêmica e do ensino superior. 2013. $290 \mathrm{f}$. Tese (Doutorado em Educação) - Universidade Federal de São Carlos, São Carlos, 2013.

ROSSO, A. J. et al. Pesquisa de Educação Ambiental em encontros regionais. Pesquisa em Educação Ambiental, Ribeirão Preto, v. 1, n.1, p. 137-158, 2009.

SILVA, T. T. Documentos de Identidade: uma introdução às teorias do currículo. 2 
TONSO, S. A. Educação Ambiental que desejamos desde um olhar para nós mesmos. Ciências em Foco, Campinas, v. 2, n. 1, p. 1-15, ago. 2010.

TREIN, E. S. A educação ambiental crítica: crítica de que? Revista Contemporânea de Educação, Rio de Janeiro, v. 7, n. 14, p. 295-308, 2012.

ZUIN, V. G.; FARIAS, C. R.; FREITAS, D. A ambientalização curricular na formação inicial de professores de química: considerações sobre uma experiência brasileira. Revista Eletrónica de Ensenãnza de las Ciencias, s/l, v. 08, n. 2, p. 552-579, 2009.

Recebido:15 mai. 2020

Aprovado: 15 jul. 2020

DOI:10.3895/actio.v5n2.12293

Como citar:

RINK, J.; MEGID NETO, J. Ambientalização curricular na Educação Superior: características e tendências de dissertações e teses brasileiras (1987-2009). ACTIO, Curitiba, v. 5, n. 2, p. 1-23, mai./ago. 2020.

Disponível em: <https://periodicos.utfpr.edu.br/actio>. Acesso em: XXX

Correspondência:

Juliana Rink

Av. Bertrand Russell, 801. Cidade Universitária "Zeferino Vaz", Campinas, SP, Brasil.

Direito autoral: Este artigo está licenciado sob os termos da Licença Creative Commons-Atribuição 4.0

Internacional.

(c) (i) 